\title{
Ação do óleo essencial de menta (Mentha arvensis) sobre o patógeno Lasiodiplodia theobromae em cachos de videira cv. Itália
}

\author{
Georgia de Souza Peixinho ${ }^{1}$, Valtemir Gonçalves Ribeiro², Edna Peixoto da Rocha Amorim³
}

\begin{abstract}
${ }^{1}$ Mestranda do Programa de Pós-graduação em Agronomia: Horticultura Irrigada (PPGHI), pela Universidade do Estado da Bahia (UNEB)/

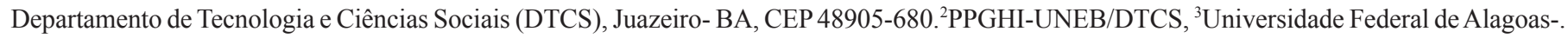
Centro de Ciências Agrárias, Rio Largo-AL, CEP 57080-000

Autor para correspondência: Georgia de Souza Peixinho (geopeixinho@gmail.com)

Data de chegada: 23/05/2016. Aceito para publicação em: 18/07/2016.
\end{abstract}

$10.1590 / 0100-5405 / 2204$

\section{RESUMO}

Peixinho, G.S.; Ribeiro, V.G.; Amorim, E.P.R. Ação do óleo essencial de menta (Mentha arvensis) sobre o patógeno Lasiodiplodia theobromae em cachos de videira cv. Itália. Summa Phytopathologica, v.43, n.1, p.32-35, 2017.

A presença de Lasiodiplodia theobromae (Podridão seca) na videira, em áreas irrigadas da região semiárida brasileira, mostra-se muito agressivo ao infectar várias partes das plantas. Os óleos essenciais apresentam eficiência no controle de doenças, tanto por sua ação fungitóxica, que inibe o crescimento micelial e a germinação de esporos, quanto pela presença de compostos eliciadores. Com isso, o presente trabalho teve por objetivo obter o controle de L. theobromae pela utilização do óleo de Menta (Mentha arvensis) em diferentes dosagens. $\mathrm{O}$ crescimento micelial de L. theobromae foi analisado em placas de Petri contendo o meio batata-dextrose-ágar suplementado com o óleo essencial nas seguintes concentrações: $0 ; 0,25 ; 0,5 ; 1,0 ; 1,5$; $2,0 \%$ de óleo de Menta Para avaliação do efeito direto do óleo essencial sobre o desenvolvimento da doença, os cachos de uva foram inoculados com o patógeno e, após $4 \mathrm{~h}$, aspergidos com soluções contendo as mesmas concentrações descritas anteriormente; posteriormente, com o objetivo de avaliar o potencial do óleo essencial no tratamento preventivo, os mesmos tratamentos foram aplicados em cachos de uva 4 horas antes da inoculação. O óleo de Menta, em todas as concentrações testadas foi capaz de inibir o crescimento micelial de L. theobromae em $100 \%$. No tratamento curativo, com relação à incidência, Menta $0,25 \%$ diferiu estatisticamente dos demais tratamentos, apresentando $88 \%$ de bagas infectadas, e em todas as concentrações não foi capaz de reduzir a severidade da podridão seca em cachos de uva. Enquanto no tratamento preventivo, com relação a incidência, o óleo de Menta $0,5 \%$ diferiu estatisticamente da testemunha, apresentando $86 \%$ e $94 \%$ bagas infectadas respectivamente, e apresentou melhor redução da severidade da podridão seca, apresentando índice de doença de $73,7 \%$ em relação a testemunha, com $98 \%$ de índice de doença.

Palavras-chave: controle alternativo, produtos naturais, podridão seca.

\section{ABSTRACT}

Peixinho, G.S.; Ribeiro, V.G.; Amorim, E.P.R. Action of the essential oil of mint (Mentha arvensis) on the pathogen Lasiodiplodia theobromae in bunches of grapevine cv. Itália. Summa Phytopathologica, v.43, n.1, p.32-35, 2017.

The presence of Lasiodiplodia theobromae (dry rot) on the vine, in irrigated areas of the Brazilian semi-arid region, has been very aggressive, infecting several plant parts. Essential oils show efficient disease control, both for their fungitoxic action, which inhibits mycelial growth and spore germination, and for the presence of elicitor compounds. Thus, this study aimed to obtain $L$. theobromae control by using the oil from mint (Mentha arvensis). The mycelial growth of $L$. theobromae was analyzed on Petri plates containing potatodextrose-agar medium supplemented with the essential oil at the following concentrations: $0 ; 0.25 ; 0.5 ; 1.0 ; 1.5 ; 2.0 \%$ of mint oil. To evaluate the direct effect of the essential oil on the disease development, the grape bunches were inoculated with the pathogen and, after $4 \mathrm{~h}$, sprayed with solutions containing the same previously described concentrations; then, to evaluate the potential of essential oil in the preventive treatment, the same treatments were applied on grape bunches at 4 hours before inoculation. The mint oil, at all tested concentrations, was capable of inhibiting the mycelial growth of $L$. theobromae by $100 \%$. In the curative treatment, considering incidence, $0.25 \%$ mint was statistically different from the remaining treatments, showing $88 \%$ infected berries, while dry rot severity of grape bunches could not be reduced by any of the concentrations. For the preventive treatment, considering incidence, $0.5 \%$ mint oil statistically differed from control, showing $86 \%$ and $94 \%$ infected berries, respectively, and there was greater reduction in dry rot severity, since the disease index was $73.7 \%$, compared to control, which had disease index of $98 \%$.

Keywords: alternative control, natural products, dry rot.

A presença de Lasiodiplodia theobromae (sin.: Botryodiplodia theobromae Pat.) em áreas irrigadas do trópico semiárido brasileiro - caracterizada por apresentar o microclima ideal para o seu desenvolvimento (10) - foi verificada nas culturas da mangueira, videira, goiabeira, laranjeira, coqueiro, tamareira, abacateiro, bananeira, limoeiro, maracujazeiro, sendo comumente conhecida como podridão seca ou morte descendente. Em todas as culturas o fungo mostravase muito agressivo infectando várias partes das plantas, causando diferentes sintomas nas plantas, desde a morte descendente ("dry-back") o cancro em raízes, caules e ramos, lesões em folhas, sementes, estacas e frutos, resultando na morte de mudas e enxertos (9).

A alternativa da utilização de métodos de controle de doenças fúngicas tem sido um desafio para o homem e, dentro desta perspectiva, o principal método utilizado é o dos compostos químicos sintéticos. Apesar de sua significativa contribuição para a produção agrícola, o uso intensivo e indiscriminado destes produtos favoreceu o surgimento de patógenos resistentes e doenças secundárias, além do comprometimento do meio ambiente e da saúde humana, por serem altamente tóxicos 
(6). Sendo assim o controle alternativos de fitopatógenos vem sendo alvo de novos estudos ao longo dos anos. Um dos focos de estudo são os chamados metabólitos secundários. As plantas produzem diversos compostos orgânicos, muitos dos quais não participam diretamente de seu desenvolvimento e desempenham um papel fundamental nas suas interações de defesa contra predadores e patógenos. (1).

A atividade antimicrobiana de óleos essenciais de Mentha piperita L. e Mentha arvensis L., foi verificada contra as bactérias Helicobacter pylori e Staphylococcus. aureus, tanto em linhagens sensíveis como resistentes a antibióticos. Pesquisadores demonstraram o efeito fungicida e fungistático desse óleo sobre 23 espécies, entre elas: Alternaria sp., Curvularia lunata, Fusarium verticillioides, F. solani e Rhizoctonia bataticola (8). Esses autores usaram concentrações que variavam de $500 \mu \mathrm{L} \mathrm{mL}^{-1}$ a $10.000 \mu \mathrm{L} \mathrm{mL}^{-1}$ de óleo de Menta nos respectivos meios de cultura e observaram inibição de $100 \%$ do crescimento micelial, a partir de $2000 \mu \mathrm{L} \mathrm{mL}^{-1}$.

Considerando o potencial de uso de produtos fitoterápicos e dos danos provocados por $L$. theobromae na viticultura, o presente trabalho teve como objetivo verificar o efeito do óleo de Menta no controle in vitro de L. theobromae e no controle preventivo e curativo da Podridão seca.

\section{MATERIAL E MÉTODOS}

Os experimentos foram conduzidos no laboratório de Fitopatologia, Centro de Ciências Agrárias (CECA) da Universidade Federal de Alagoas (UFAL), em Rio Largo.

Para a realização deste estudo, óleo essencial de Menta (Mentha arvensis) foi adicionado ao meio de cultura batata-dextrose-ágar (BDA), fundente $\left(45-50{ }^{\circ} \mathrm{C}\right)$, vertido em placas de Petri de $9 \mathrm{~cm}$ de diâmetro, usando-se 6 placas para cada tratamento:: $0 ; 0,25 ; 0,5 ; 1,0 ; 1,5 ; 2,0 \%$. Todas as concentrações de óleos foram esterilizadas pela ação de luz UV por 30 minutos antes de serem adicionados ao meio autoclavado (2).

No centro de cada placa foi depositado um disco de meio BDA de $0,6 \mathrm{~cm}$ de diâmetro, contendo micélio fúngico, retirado das bordas da colônia do patógeno. Após a incubação por cinco dias à temperatura de $28^{\circ} \mathrm{C}$ e fotoperíodo de 12 horas, foi determinado o diâmetro médio da colônia tomado no reverso das placas de Petri, através da medição em dois sentidos diametralmente opostos, e por comparação com o crescimento das colônias nas placas testemunhas, que receberam o meio de cultura sem tratamentos, foi calculado a Percentagem de Inibição do Crescimento micelial (P.I.C.), pela diferença entre o crescimento da testemunha e o crescimento do tratamento dividido pelo crescimento da testemunha, multiplicado por 100 (5), expresso por:

\section{P.I.C. $=(\underline{\text { crescimento testemunha }- \text { crescimento tratamento }) * 100}$ crescimento testemunha}

$\mathrm{Na}$ avaliação do efeito direto dos extratos sobre o desenvolvimento de L. theobromae, cachos da videira cv. Itália adquiridos em mercado local na cidade de Maceió, tratadas com hipoclorito de sódio 0,1\% e mantidas em temperatura ambiente, foram inoculados com o patógeno, realizando-se ferimentos nas bagas com o uso de lâminas esterilizadas, direcionando-se, em seguida, jatos de suspensão de conídios, preparada adicionando $10 \mathrm{ml}$ de água destilada esterilizada (ADE) em uma placa contendo cultura pura do patógeno, realizou-se a raspagem com o auxilio de uma escova de cerdas macias, logo após o material foi filtrado em gaze dupla esterilizada e utilizando uma câmara de Neubauer foi ajustada $\left(10^{5}\right.$ conídios. $\left.\mathrm{mL}^{-1}\right)$ para cada cacho, e, após $4 \mathrm{~h}$, foram aspergidas as soluções de óleos essenciais de Menta $(0,25 ; 0,5 ; 1,0$; 1,$5 ; 2,0 \%$ ), utilizando-se água destilada esterilizada como testemunha. As pulverizações foram realizadas com jatos direcionados aos cachos, aplicando-se $10 \mathrm{~mL}$ da solução por cacho, utilizando-se a mesma metodologia para todos os tratamentos. Em seguida, os cachos foram dispostos sobre papel absorvente para retenção do excesso de umidade e posterior secagem sob ventilação (Ensaio 1).

Os cachos foram acondicionados em sacos plásticos e mantidos a $25 \pm 1^{\circ} \mathrm{C} / 80-90 \%$ de umidade relativa (UR), por 48 horas (ambiente de câmara úmida), e avaliados após o período de seis dias.

Posteriormente, com o objetivo de avaliar o potencial do óleo essencial em tratamento preventivo, os cachos foram aspergidos com as soluções de óleo, nas mesmas concentrações e testemunha, e após 4 horas foram inoculados com o fungo L. theobromae (Ensaio 2).

No ensaio 2, os cachos também foram dispostos sobre papel absorvente para retenção do excesso de umidade e secagem sob ventilação, onde permaneceram a $25 \pm 1{ }^{\circ} \mathrm{C} / 85-95 \%$ UR até o momento da inoculação. Os cachos que haviam sido inoculados quatro horas depois do tratamento foram igualmente acondicionados em sacos plásticos e mantidos a $25 \pm 1{ }^{\circ} \mathrm{C} / 80-90 \%$ UR, por 48 horas e avaliados após um período de seis dias, quanto à incidência e severidade perante escala de notas que variou no intervalo de 1 a 6, baseada na área da lesão, correspondendo, aproximadamente, a 2, 5, 10, 20, 30 e $50 \%$ da área lesionada da baga, respectivamente. Os resultados expressos em índice de doença sendo calculado através da fórmula: ID $(\%)=$ $\{[(\mathrm{n} 1 \mathrm{x} 1)+\ldots+(\mathrm{n} 6 \mathrm{x} 6)] \times(6 \mathrm{xN})-1\} \times 100$, onde, $\mathrm{n} 1 \ldots 6=\mathrm{n}^{\circ}$ de bagas infectadas com a respectiva nota e $\mathrm{N}=\mathrm{n}^{\circ}$ total de bagas inoculadas, adaptada para L. theobromae (3).

$\mathrm{O}$ delineamento experimental utilizado para cada ensaio foi o inteiramente casualizado, com seis tratamentos e cinco repetições. Os dados foram submetidos à análise de variância, teste $\mathrm{F}$, e quando os efeitos de tratamentos apresentarem diferença significativa $(P<0,01)$ as médias foram comparadas por meio do teste de regressão.

\section{RESULTADOS E DISCUSSÃO}

De acordo com os dados apresentados na Tabela 1, o óleo de Menta, em todas as concentrações, foi capaz de inibir em $100 \%$ o crescimento micelial de $L$. theobromae in vitro.

Outros resultados no controle de fungos do gênero Fusarium demonstraram o efeito fungicida e fungistático do óleo de Menta (Mentha $\mathrm{sp)}$ sobre 23 espécies de patógeno fúngicos, entre eles: Alternaria sp, Curvalaria luneta, F. moniliforme, F. solani e Rhizoctonia bataticola. Os autores usaram concentrações de 500 a $10.000 \mathrm{mg} \mathrm{mL}^{-1}$ do óleo nos respectivos meios de cultura, registrando total inibição do

Tabela 1. Crescimento Micelial de fungo Lasiodiplodia theobromae em presença de óleo essencial de menta em diferentes concentrações.

\begin{tabular}{ccccccc}
\hline \multicolumn{7}{c}{ Crescimento Micelial* $(\mathrm{cm})$} \\
\hline Conc. (\%) & $0 \%$ & $0.25 \%$ & $0.5 \%$ & $1 \%$ & $1.5 \%$ & $2 \%$ \\
\hline $9.0 \mathrm{a}$ & $0.0 \mathrm{~b}$ & $0.0 \mathrm{~b}$ & $0.0 \mathrm{~b}$ & $0.0 \mathrm{~b}$ \\
\hline \multicolumn{7}{c}{ Letras iguais não diferem significativamente no teste de Tukey a $5 \%}$.
\end{tabular}




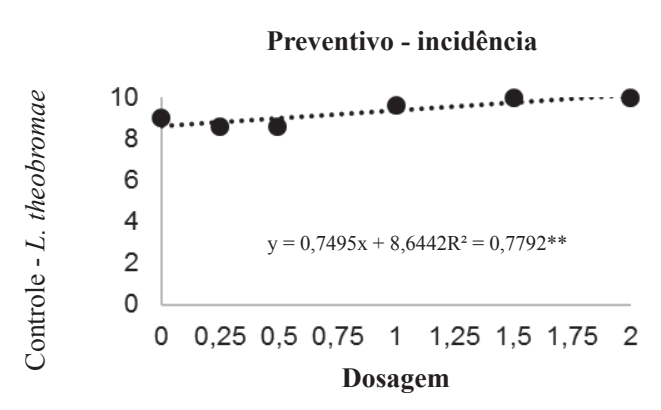

Curativo - severidade

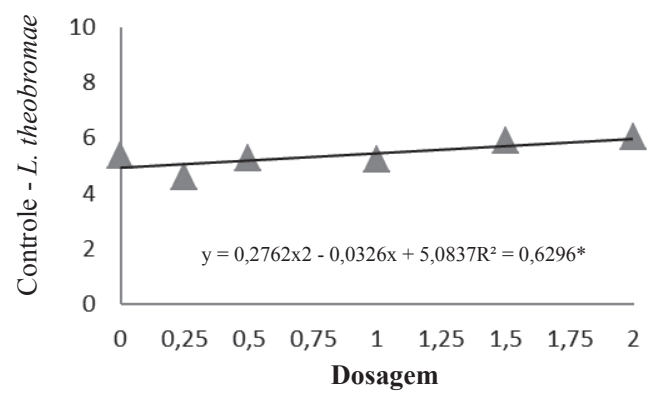

Preventivo - severidade
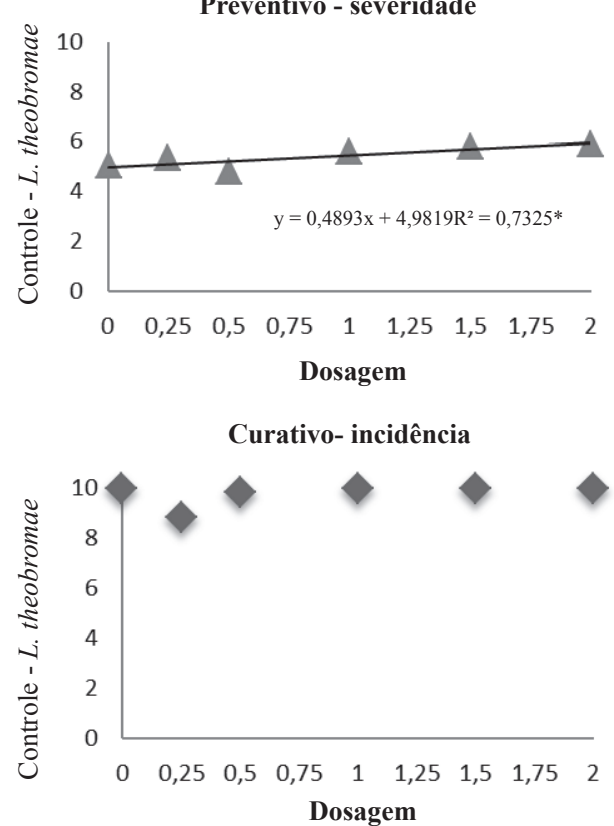

Figura 1. Óleo essencial de menta em diferentes concentrações no tratamento curativo e preventivo de Lasiodiplodia theobromae em cachos de uva cv. Itália avaliados no sexto dia após a inoculação.

crescimento micelial, a partir de $2.000 \mathrm{mg} \mathrm{mL}^{-1}$ (8), resultados que corroboram com este trabalho.

Ao se utilizar óleos essenciais de condimentos: Orégano, Alecrim, Manjericão, Menta e Cebola, foi possível verificar a inibição do crescimento de diversos fungos (Aspergillus niger, A. flavus, A. ochraceus, Fusarium sp.) a medida que aumentava a concentração desses óleos (4).

Com relação à incidência da doença no tratamento curativo pode-se observar que apenas Menta a 0,25\% diferiu estatisticamente de todos os tratamentos, apresentando $88 \%$ de bagas infectadas; os demais apresentaram $100 \%$ de bagas infectadas (Tabela 2).

O óleo de Menta em todas as concentrações não foi capaz de reduzir a severidade da podridão seca em cachos de uva, não diferindo significativamente da testemunha.

Com relação à incidência da doença no tratamento preventivo, pode-se observar que o óleo de Menta a $0,5 \%$ diferiu estatisticamente da testemunha, apresentando $86 \%$ e $94 \%$ bagas infectadas, respectivamente; seguido dos tratamentos 0,25 e 1\%. O óleo de Menta a $0,5 \%$ apresentou menor severidade da podridão seca, apresentando índice de doença de 73,7\% enquanto à testemunha apresentou $98 \%$ de índice de doença (Figura 1).

Testes com óleos essenciais de Pogostemon cablin, Mentha arvensis, Cymbopogon citratus, Ocimum basilicum var. Maria bonita, Ocimum gratissimum, Pogostemom cablin, Romarinus officinalis, Salvia officinalis, Lippia sidoides, Zingiber officinale, Citrus aurantifolia, Piper aduncum e Ocimum basilicum, nas concentrações de 1 a $100.000 \mathrm{mg} \mathrm{L}^{-1}$, não surtiram efeitos para o controle da Pinta preta em frutos de laranja (7), diferindo dos resultados obtidos neste trabalho.

Avaliando o controle in vivo da antracnose na fase pós-colheita do Mamão (Colletotrichum gloeosporioides), com o uso de óleos essenciais de Cymbopogon citratus (Capim-limão), Corymbia citriodora (Eucalipto), Mentha arvensis (Menta) e Artemisia dracunculus (Estragão), foi possível constatar o potencial desses óleos no controle da doença (4), corroborando com os dados encontrados neste trabalho.

Os óleos essenciais de Pogostemon cablin, Mentha arvensis, Cymbopogon citratus, Ocimum basilicum L. (cultivar Maria bonita), Rosmarinus officinalis, Lippia sidoides, Zingiber officinale, Citrus aurantifolia, Piper aduncum e Ocimum basilicum nas concentrações de $10.000 \mu \mathrm{l} \mathrm{mL} L^{-1}$ e $100.000 \mu 1 \mathrm{~mL}^{-1}$ foram eficientes em controlar o Bolor-verde-da-laranja, causado por $P$. digitatum, quanto à inibição da germinação e no crescimento micelial do fungo; todavia, não foram verificadas diferenças significativas entre as aplicações dos óleos nos períodos $24 \mathrm{~h}$ antes, simultaneamente, e $24 \mathrm{~h}$ depois da inoculação do patógeno (7).

Com os resultados obtidos neste trabalho conclui-se que o óleo de Menta, nas concentrações testadas, foi capaz de inibir o crescimento micelial de $L$. theobromae em $100 \%$; para o tratamento curativo, em relação à incidência, a concentração de $0,25 \%$ reduziu em $22 \%$ a infecção de bagas de uvas inoculadas com L. theobromae, mas não foi capaz de reduzir a severidade da doença nas concentrações testadas. No tratamento preventivo, o óleo de Menta a 0,5\%, reduziu em $14 \%$ a infecção das bagas, e a severidade em $26,3 \%$. Estudos mais detalhados e em condições diferentes de armazenamento são necessários para a confirmação da eficiência do óleo de menta no controle da podridão seca na videira.

\section{REFERÊNCIAS}

1.Andrade, S. P. Avaliação da atividade antifúngica de extratos de Cassia fistula (Leguminosae). Revista PIBIC, Osasco, v.3, n.2, p. 151-158, 2006.

2.Barguil, B.M. et al. Ocorrência de Colletotrichum gloeosporioides em Heliconia chartacea cv. Sex Pink. Fitopatologia Brasileira, Brasília, v.30, p.S136. 2005.

3.Camili, E. C.; Benato, E. A.; Pascholati, S. F.; Cia, P. Avaliação de quitosana, aplicada em pós-colheita, na proteção de uva 'Itália' contra Botrytis cinerea. 
Summa Phytopathologica, Botucatu, v.33, n.3, p.215-221, 2007.

4.Carnelossi, P. R.; Schwan-Estrada, K. R. F.; Cruz, M. E. S.; Itako, A. T.; Mesquini, R. M. Óleos essenciais no controle pós-colheita de Colletotrichum gloeosporioides em mamão. Revista Brasileira de Plantas Medicinais, Botucatu, v.11, n.4, 2009.

5.Edington, L.V.; Khew, K.L.; Barron, G.L. Fungitoxic spectrum of benzimidazole compounds. Phytopathology, São Paulo, v.61, n.1, p.42-44, 1971.

6.Marques, R. P.; Monteiro, A. C.; Pereira, G. T. Crescimento, esporulação e viabilidade de fungos entomopatogênicos em meios contendo diferentes concentrações do óleo de nim (Azadirachta indica). Ciência Rural, Santa Maria v.34, p.1675-1680, 2004.

7.Mattos, L.P.V. Controle de Guignardia citricarpa E Penicillium digitatum em laranja com óleos essenciais e agentes de biocontrole. 2010. 104p. Tese (Doutorado), Universidade Estadual Paulista "Júlio de Mesquita Filho" Faculdade de Ciências Agronômicas, Botucatu.

8.Singh, H. N. P.; Prasad, M. M.; Sinha, K. K. Efficacy of leaf extracts of some medicinal plants against disease delve lop ment in banana. Letters in Applied Microbiology, v.17, n.6, p.269-271, 1993.

9.Tavares, S. C. C. H. Epidemiologia e manejo integrado de Botryodiplodia theobromae - Situação atual no Brasil e no mundo. Fitopatologia Brasileira, Fortaleza, v.27, p. S46-S52, 2002.

10.Tavares, S. C. C. de H. e Amorim, L. R. Levantamento de Botryodiplodia theobromae em áreas irrigadas do trópico semi-árido brasileiro. Fitopatologia Brasileira, Brasília v.20, supl., p.326, 1995. (Resumo). 